\title{
ОЦЕНКА РИСКОВ СТРУКТУРНЫХ ПОСТРОЕНИЙ И ОПРЕДЕЛЕНИЯ ВЕЛИЧИНЫ РЕСУРСОВ УГЛЕВОДОРОДОВ ОДНОГО ИЗ МЕСТОРОЖДЕНИЙ ЗАПАДНОЙ СИБИРИ.
}

Пииенова АМ., Степанов А.B.

(ОАО «Центральная Геофизическая Экспедиџия", Москва, Россия)

В данной работе рассмотрена методика оценки рисков структурных построений и определения величины ресурсов углеводородов на основе стохастического моделирования.

При оценке неопределенности величины ресурсов необходимо учитывать неопределенность пространственных параметров и коллекторских свойств. В представленной работе рассматривались только нсопрсдслснности пространственных характеристик.

При оценке ресурсов УВ значительная часть неотределенности результата вызвана наличием погрепностей в межскважкином пространстве при построении структурных поверхностей и эффективной толщииы пласта. Чтобы учесть влияние всей совокупности факторов риска, проводится серия испытаний, в каждом из которых учитываемые параметры отличаются от исходных данных в пределах заданного уровня их возможного разброса.

В данной работе исходными данными являлись пространственные характеристики залежи, полученные по данным сейсморазведки, положение газо-водяного контакта, определенное по данным бурения и емкостные параметры, определенные также по данным бурения.

Работа выполнялась с учетом данных сейсморазведки $3 Д$, поэтому величина среднеквадратичной ошибки была определена на основе выборки ошибок в точках скважин, и составила 8 метров для структурных построений и 1,5 метра для эффективных толщин.

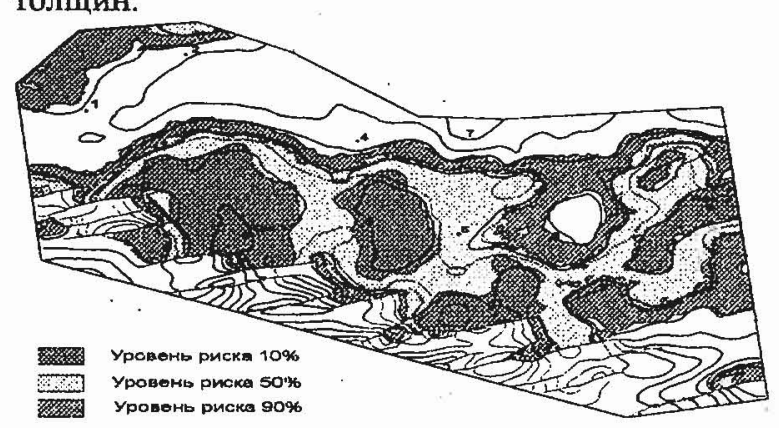

Рис. 1. Карта достоверности

Для оценки неопределенностей построения структурных поверхностей было выполнено 200 реализаций. В каждой из них была смоделирована карта ошибок, значения которой менялись в пределах величины среднеквадратичной ошибки в межскважинном пространстве.

В точках скважин вероятность неотределенности исключена, поэтому величина ошибки в них равна нулю. При выполнении серии испытаний, в ходе которых на исходную структурную карту (сначала кровлю (Тop), а затем подошву (Bot) коллектора) каждый раз накладывались полученные карты ошибок, были получены возможные реализации карт структурных построений. Затем с учетом заданного уровня ГНК была получена карта достоверности попадания каждой ячейки плоцади в залежь (рис.1). На карте выделены области локализации залежи при уровнях риска $10 \%, 50 \%$ и $90 \%$. Разброс этих контуров позволяет визуально оценить степень неопределенности, вызванную ошибками структурных построений (рис.1). Таким образом мы получили карту, согласно которой с 10\% уровнем риска можно рекомендовать две структуры для дальнейшего разбуривания.

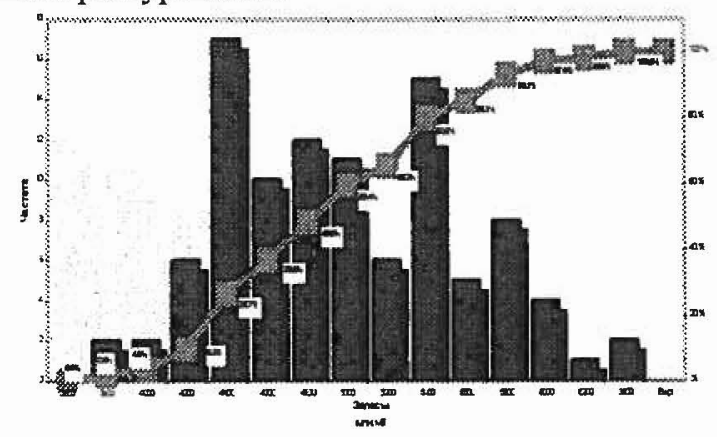

Рис.2.Гистограмма и функция риска величипы запасов

Для оценки рисков определения величины ресурсов необходимо оценить объем залежи. Для этого по описанному выше принципу была выполнена серия испытаний, в которой получены возможные варианты реализаций карты эффективных толщин (Heff). С использованием ранее полученных итераций структурных карт удалось рассчитать карты общих нефтенасыщенных толщин (GRToil) по формуле: GRToil=max(Top-ГВK;0). Следует отметить, что для каждой карты мы получили по 200 возможных реализаций. Карты эффективных толщин (NRToil) расчитывалить по формуле: NRToil= GRToil* Heff/( Top- Bot). Приведенная формула показывает, что в ЧГЗ приншипиальной является ошибка эффективной толщины, а в ВГЗ - ошибка структурных построений. По полученным реализациям карт было вычислено 200 возможных значений объема залежи. С учетом имеющихся данных (емкостных параметров) удалось выполнить расчет величины запасов. Для визуализации распределения величины запасов мы построили гистограмму и функциюо риска (рис.2). Полученная гистограмма наглядно показывает, что с наибольшей долей вероятности на рассматриваемой площади можно получить 4400 млн. ${ }^{3}$ газа. Стоит отметить, что в предыдущей работе, выполненной без применения стохастики, было получено 4090,7 млн.м ${ }^{3}$ газа, что свидетельствует о довольно высокой степени достоверности предложенного метода.

ЛИТЕРАТУРА:

O.Dubrule.Geostatistics for Seismic Data Integration in Earth Models. EAGE,2003.

Иванова Н.Л., Авербух А.Г. Оценка геологического риска при подсчете ресурсов углеводородов. В журн. "Технологии ТЭК», Нефть и Капитал, №2 (15),2004. 